\title{
Tax climate manipulation on individual tax behavioural intentions.
}

\begin{abstract}
Purpose The purpose of this paper is to extend the slippery slope framework by exploring different dimensions of compliance quality and tax minimisation under different tax climate manipulation by groups. Design/methodology/approach The authors run a random assignment of tax climate manipulations through questionnaire with 301 usable data collected from the fulltime postgraduate students, employed individuals and self-employed individuals. Manipulation check and results are generated via multivariate analysis of variance. Findings The results confirm the biggest impact of synergistic climate on voluntary compliance, and small to medium impact of antagonistic climate on tax evasion across three groups. Research limitations/implications The manipulation of this research is constrained with two treatments in addition to the common pitfall of social desired responses of self-report. Practical implications Theoretically, this study empirically explores tax minimisation dimensions and provides new insights that only illegal tax minimisation is at maximum under the prevailing negative antagonistic climate, but not for legal tax minimisation. Second, the effect of tax climate represented by trust and power on enforced compliance is minimal, as compared to the strong effect of positive synergistic climate on voluntary compliance. As for policy implications, possible guidelines and interventions are outlined to policy makers which would lead to a better quality of compliance behaviour. Originality/value This study operationalises and manipulates tax climate from perceptions of trust, legitimate power and coercive power. It also further affirms the prior inconsistent findings in respect of tax behavioural intentions due to sampling group and cultural differences.
\end{abstract}

Keyword : Compliance quality; Legality; Tax climate; Tax minimization. 